بررسى اثر همافزايى عصاره ترخون (Artemisia dracunculus) و آسبيرين (ASA) بر روى فعاليت پِاكتى

اميرحسين حيدريان'، محسن حميديور ׳*، عبدالمجيد آيتالهى"، مهدى اله بخشيان فارسانى '

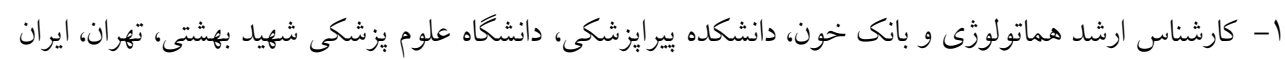

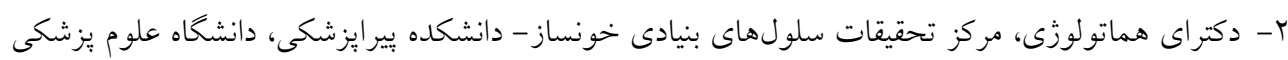

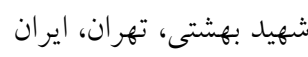

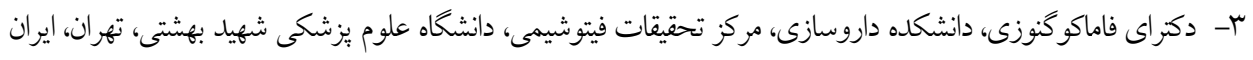

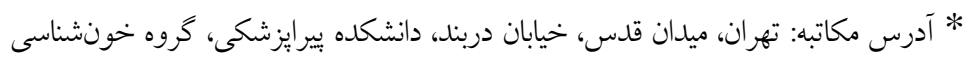

صندوقيستى:

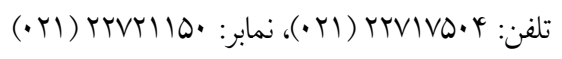
يست الكترونيك: mohsenhp@sbmu.ac.ir

doi: 10.29252/jmp.2.70.87 9V/r/V تاريخ تصويب

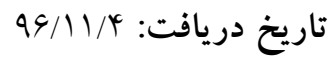

جكيده

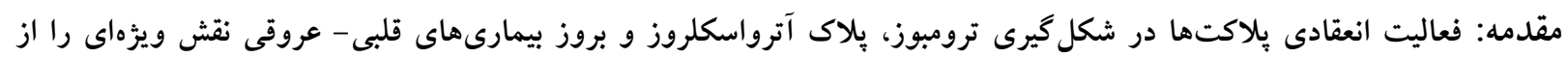

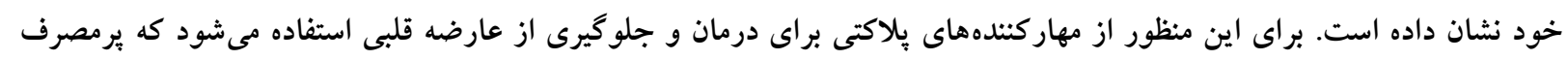

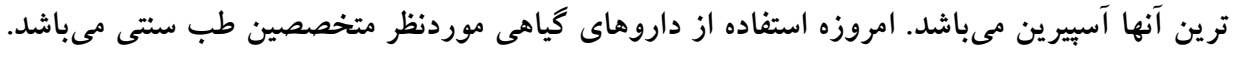

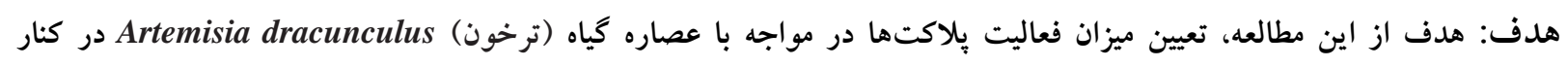

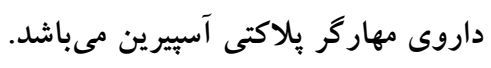

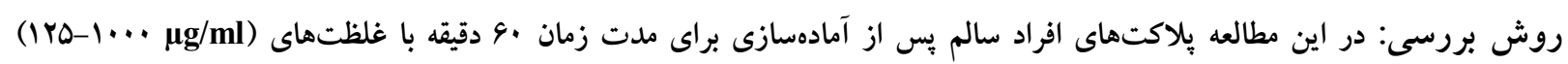

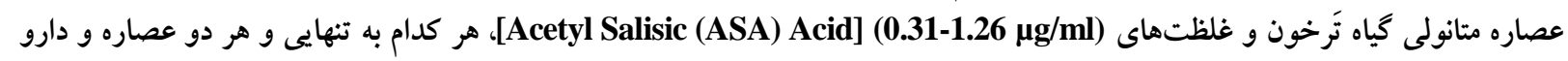

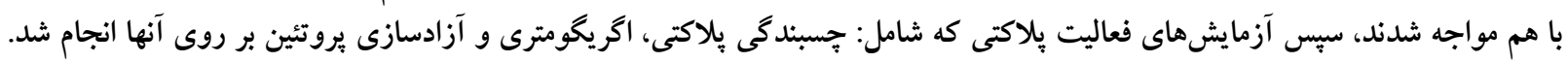

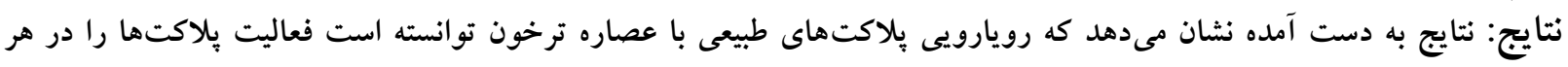

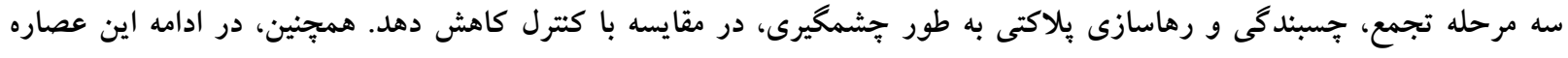

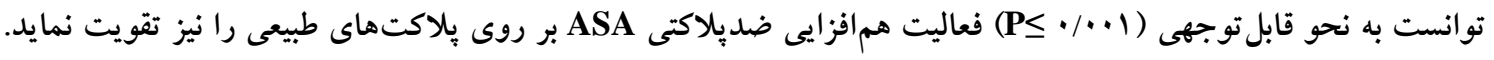

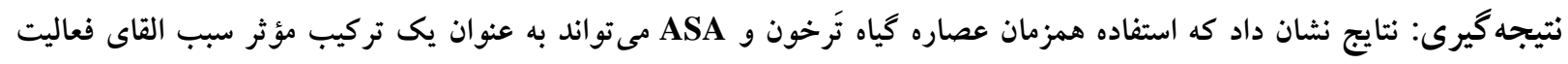

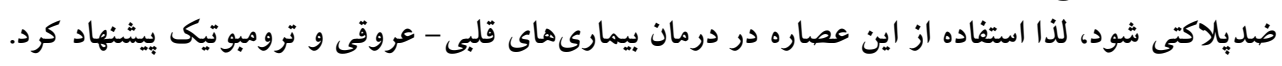

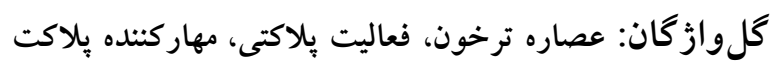


ميزان اثر سينرزيك ASA با عصاره كياه ترخون بر فعاليت

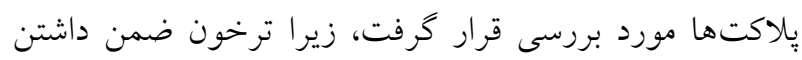

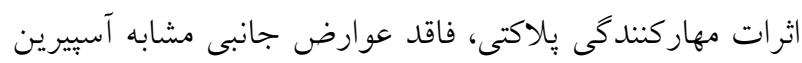

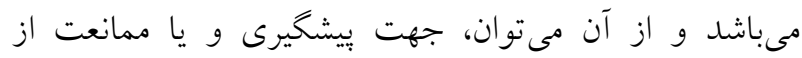
يشرفت بيمارىهاى قلبى عروقى بهره برد.

\section{مواد و روشها تهيه و عصاره گيرى گياه} كياه ترخون كونه (Artemisia dracunculus L.) مورد عيهاه بررسى را با توجه به اطلاعات موجود در كتاب فلور ايرانيكا

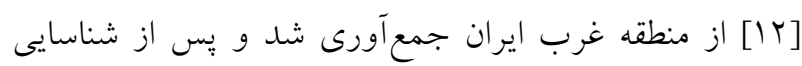

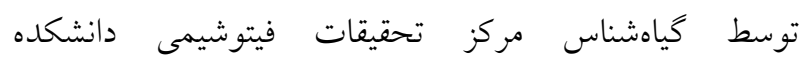

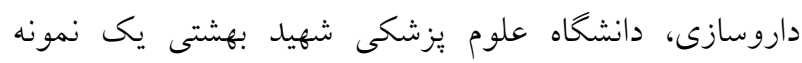

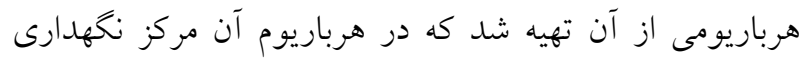

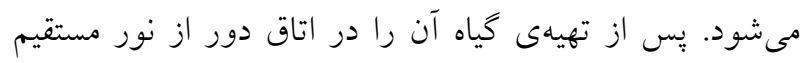

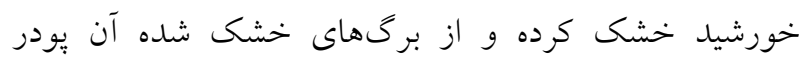

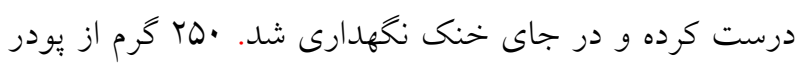

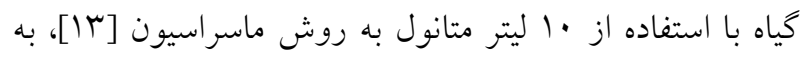

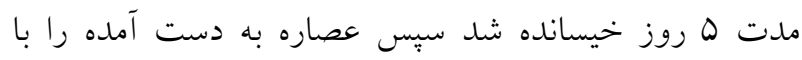

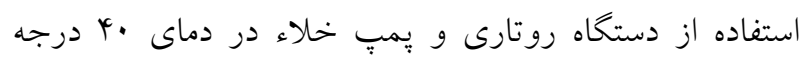

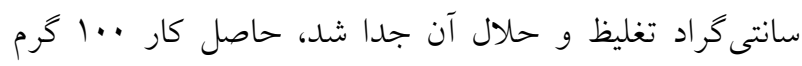

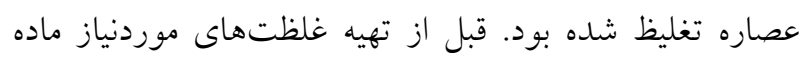

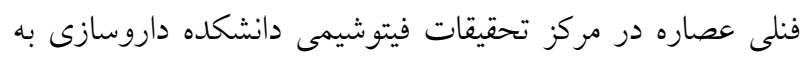

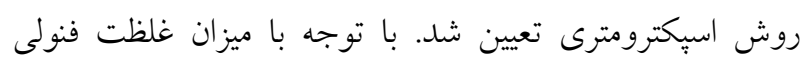

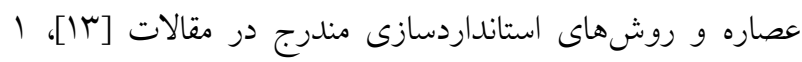

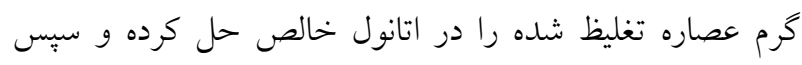

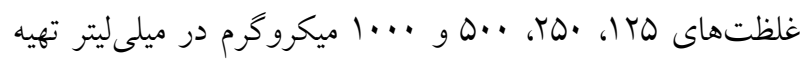

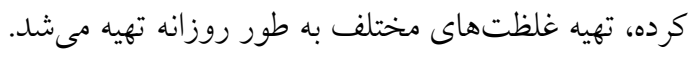

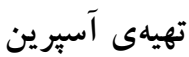

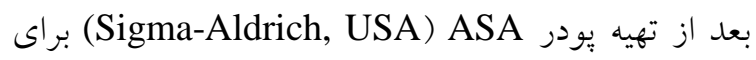

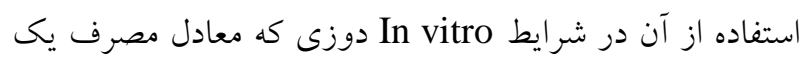

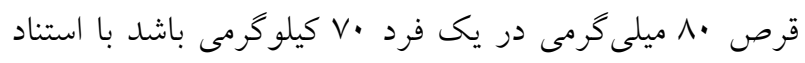

مقلم مه

آترواسكلروز يا تصلب شرايين يكى از اصلى ترين علت-

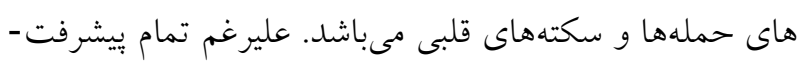

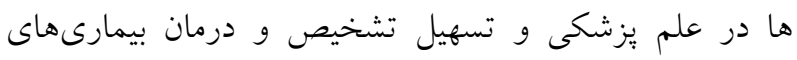

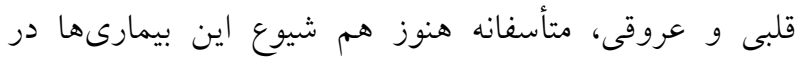

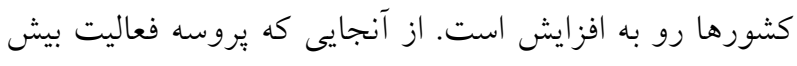

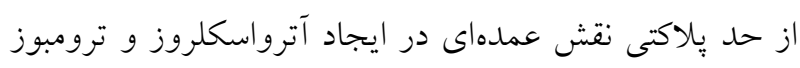

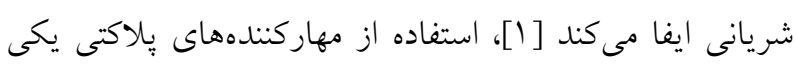

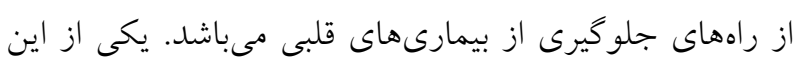

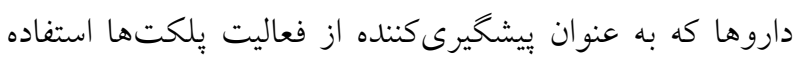

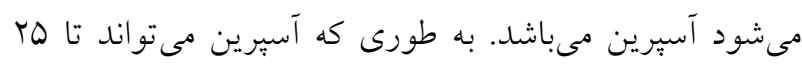

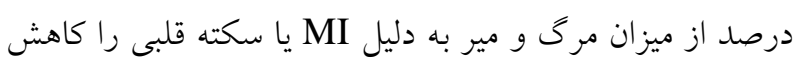

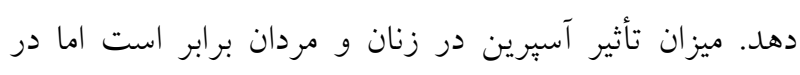

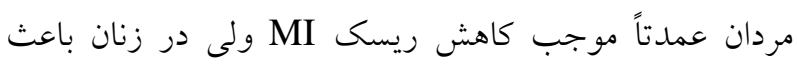

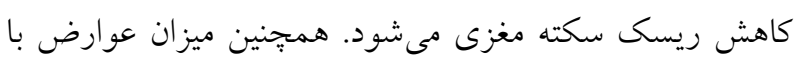

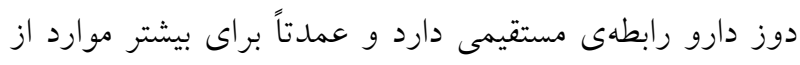

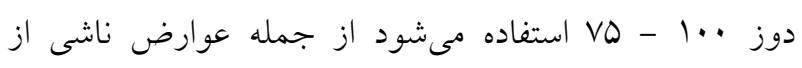

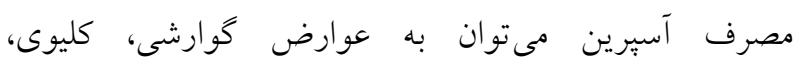

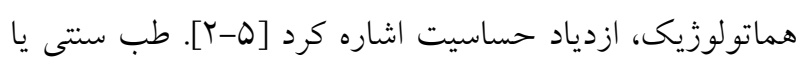

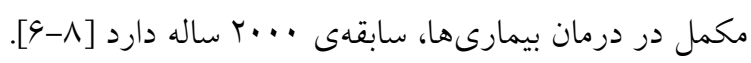
Artemisia dracunculus L. (Tarragon) صورت گسترده در دنيا و ايران به عنوان يك سبزى صرف مى آنى

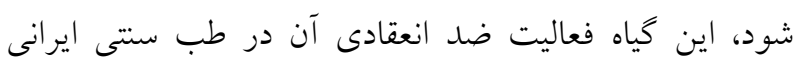
شناخته شده است [9].

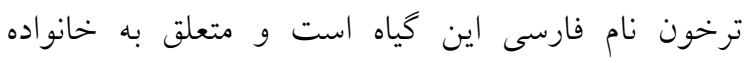
Asteracea

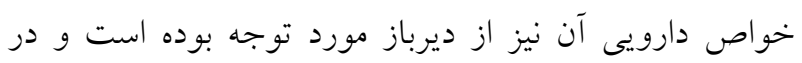

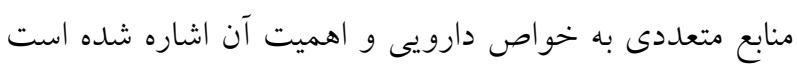

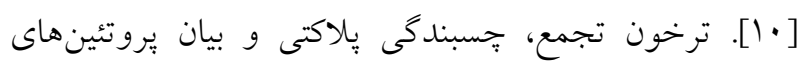

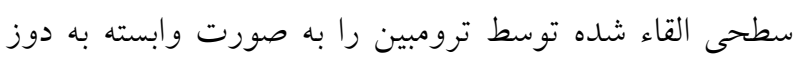

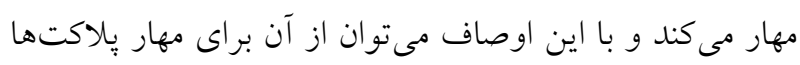

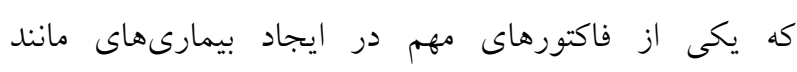

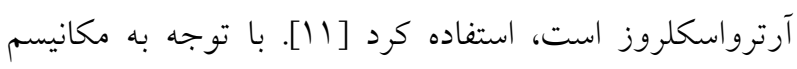

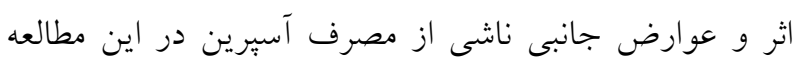


حاوى بروتئين آزاد شده يِاكت است كه طبق روش Lowry

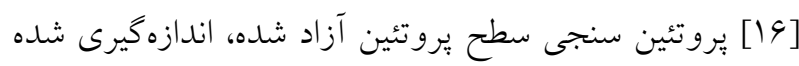

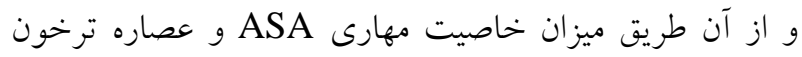

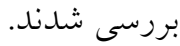

نتايج

تعيين ميزان ماده فنولى عصاره ميزان ماده فنولى عصاره ترخون را توسط اسيكتروفتومترى

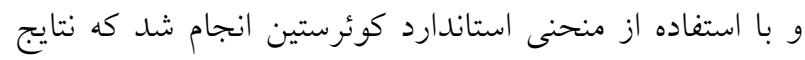
آن در جدول شماره ا منعكس شده است.

ميزان تجمع بلاكتهاى خون در مواجه با عصاره ترخون و آسييرين

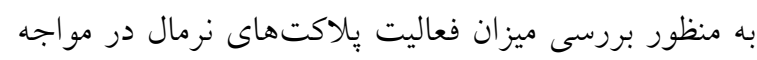
با عصارهى ترخون از آزمون اخريخومترى استفاده نموديم.

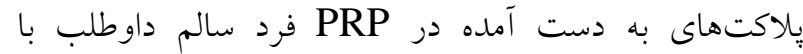

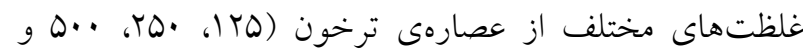

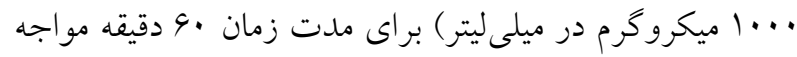

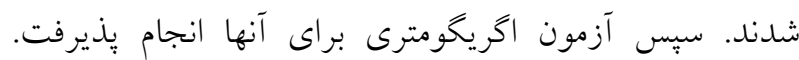

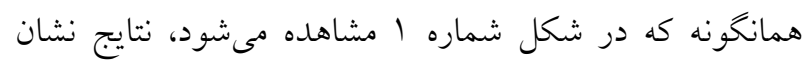

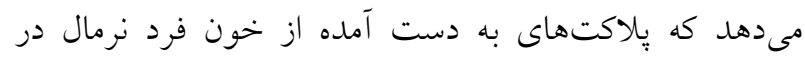

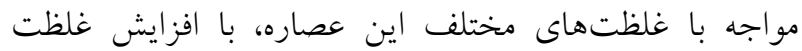

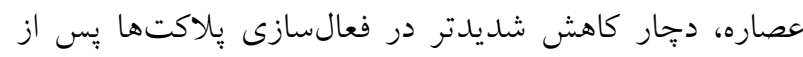

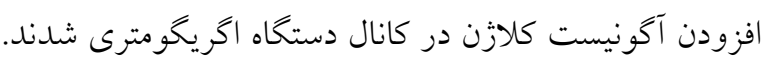

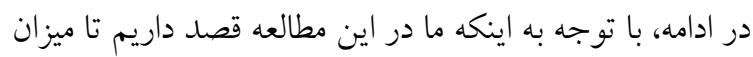

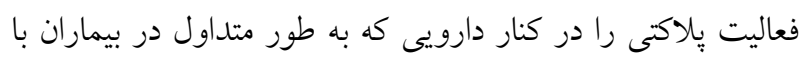

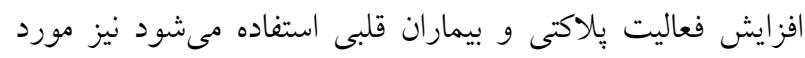

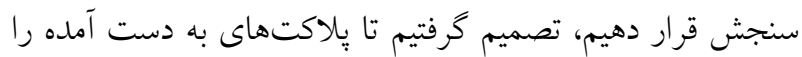

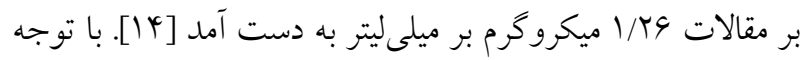

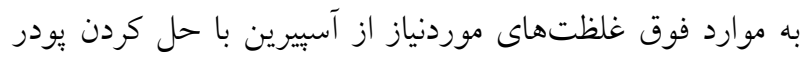
آسبيرين در بافر به (PBS) Phosphate Buffer Saline تهيه شد.

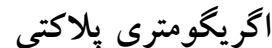
در اين تست عملكرد هِلاكت در in vitro از نظر تجمع و و

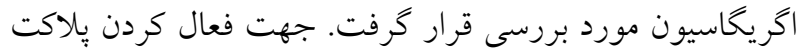

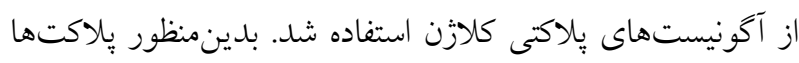

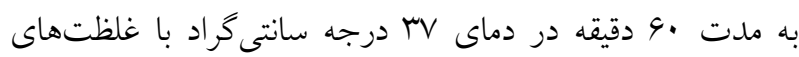

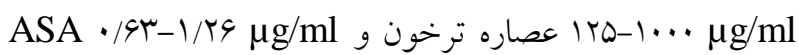

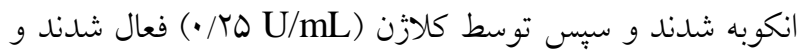
ميزان تجمع بِلاكتها توسط دستخاه اكريخومترى (CHRONO-) (LOG - Model 700

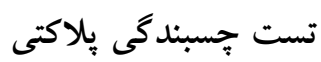

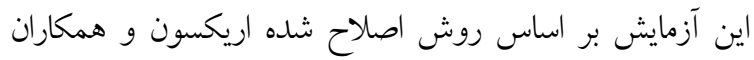

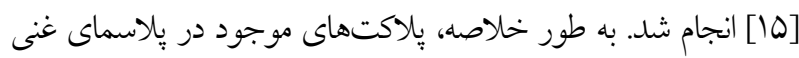

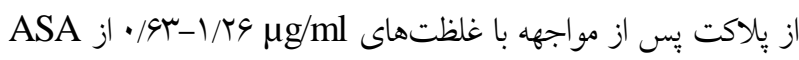

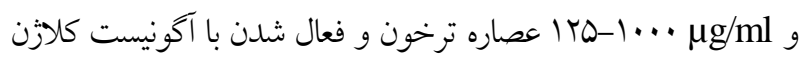

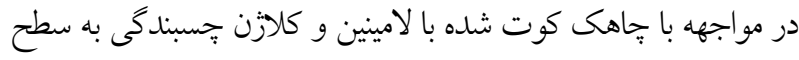

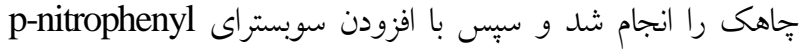
phosphate

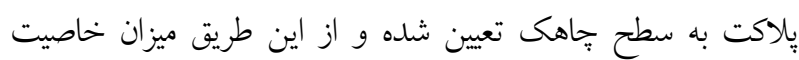
مهارى ASA و عصاره ترخون بررسى و با كترل مقايسه شدند.

$$
\text { تست ترشح بروتئين }
$$

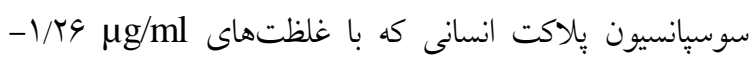

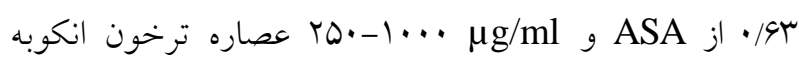

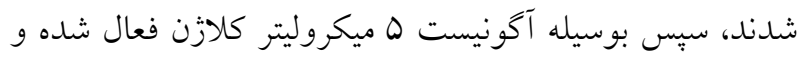

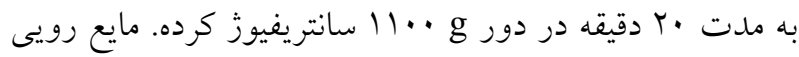

جدول شماره 1 - ميزان ماده فنولى عصاره ترخون

\begin{tabular}{cccc}
\hline Concentration $(\mu \mathrm{g} / \mathrm{ml})$ & Total phenol/quercetin $(\mu \mathrm{g} / \mathrm{ml})$ & Total Phenol\% \\
\hline $\mathrm{H} .$. & $1 \cdot / 1 \mathrm{~V}$ & $\mathrm{r} / \Delta \mathrm{Yr}$ \\
\hline
\end{tabular}




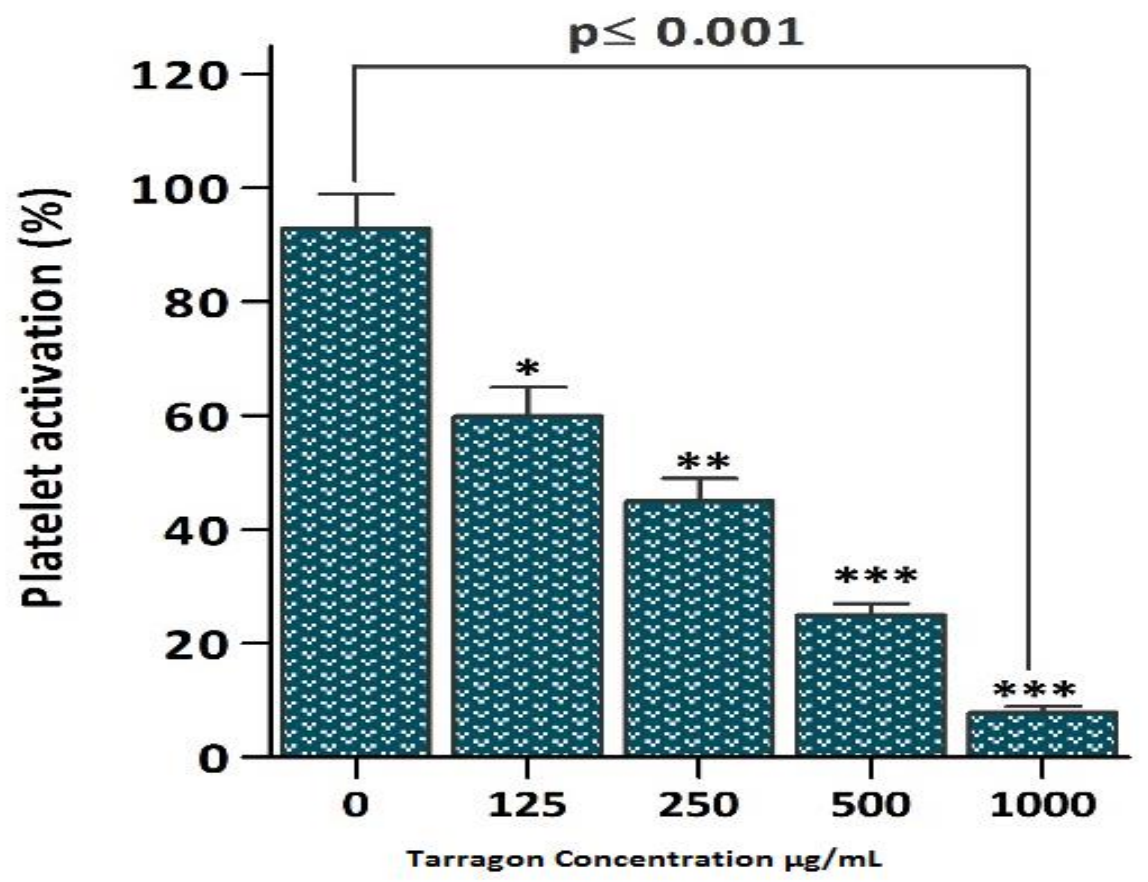

شكل شماره 1 - نتايج به دست آمده نشان مىدهد كه افزايش غلظت عصاره ترخون با كاهش فعاليت يلاكتى همراه است. ميانگين و انحراف معيار نتايج

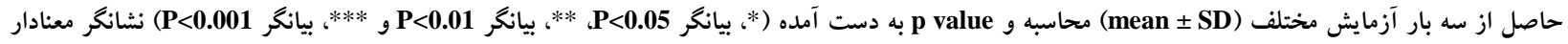
بودن نتايج از نظر آمارى در مقايسه با نمونه كنترل بود دانس

عوامل نيز به دست آمل، درنتيجه در اين قسمت به بررسى تأثير

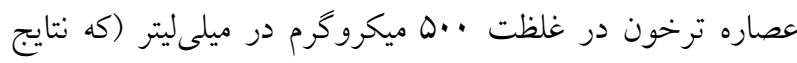
مناسبترى نسبت به ساير غلظتها داشت) در كنار غلظتهاى

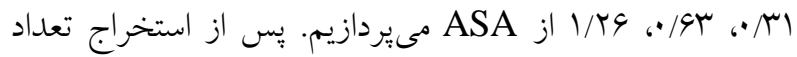

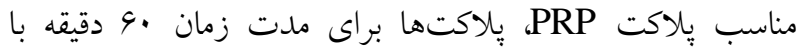

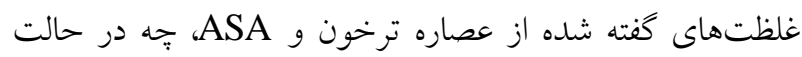

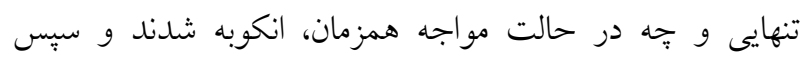

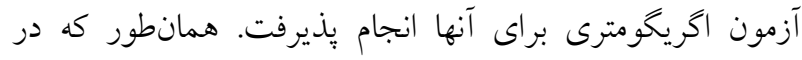

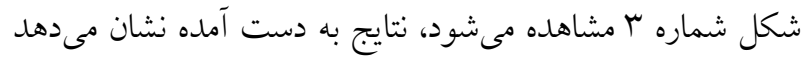
كه استفاده همزمان عصاره ترخون و ASA توانسته است ميزان

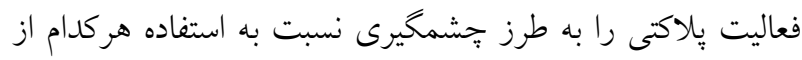

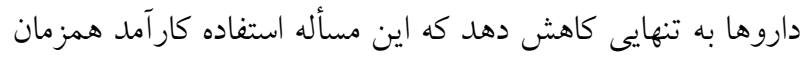
از عصاره ترخون و ASA را نشان مى دهد.
با غلظتهاى مختلف داروى ASA نيز مواجه كنيم. بدينمنظور

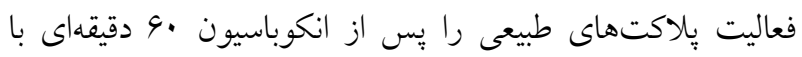
غلظتهاى مختلف ASA، بِ از فعالسازى با آكونيست كلازّن، در دستخاه اخريخومترى مورد سنجش قرار داديم كه نتايج حاصله در شكل شماره Y نشان داده شده است.

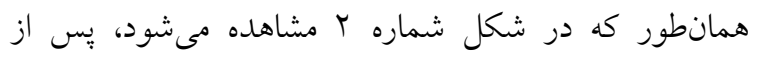

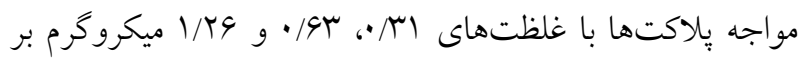

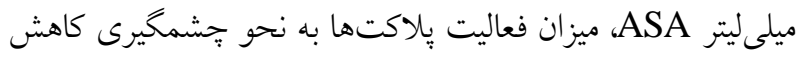

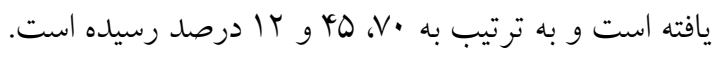

بررسى ميزان تجمع بِلاكتهاى خون در مواجه همزمان با عصاره ترخون و ASA با توجه به اينكه زمان مناسب براى انكوباسيون دارو و و ورد

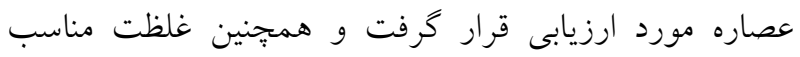




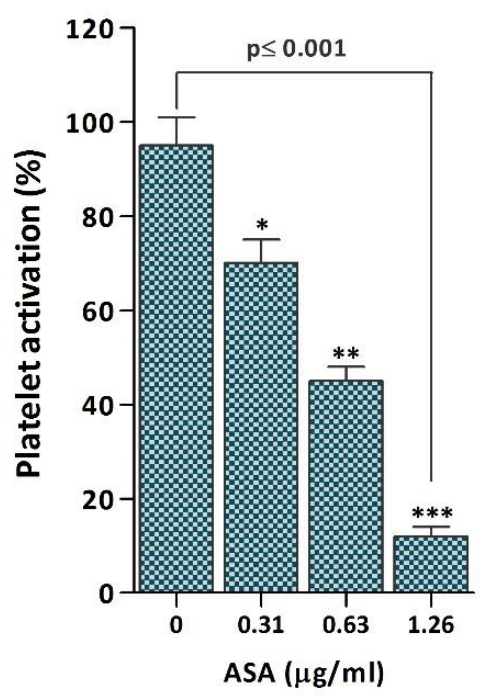

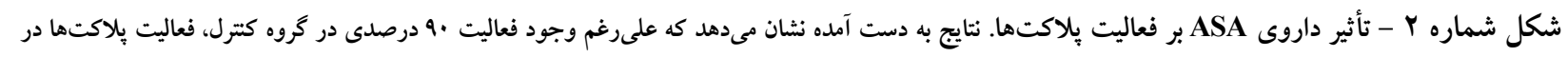

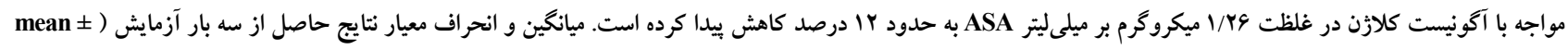

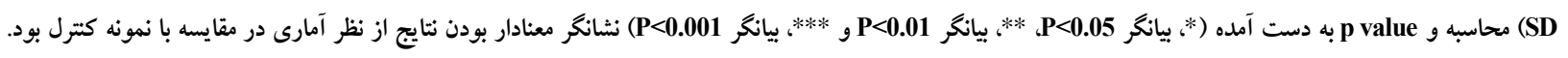

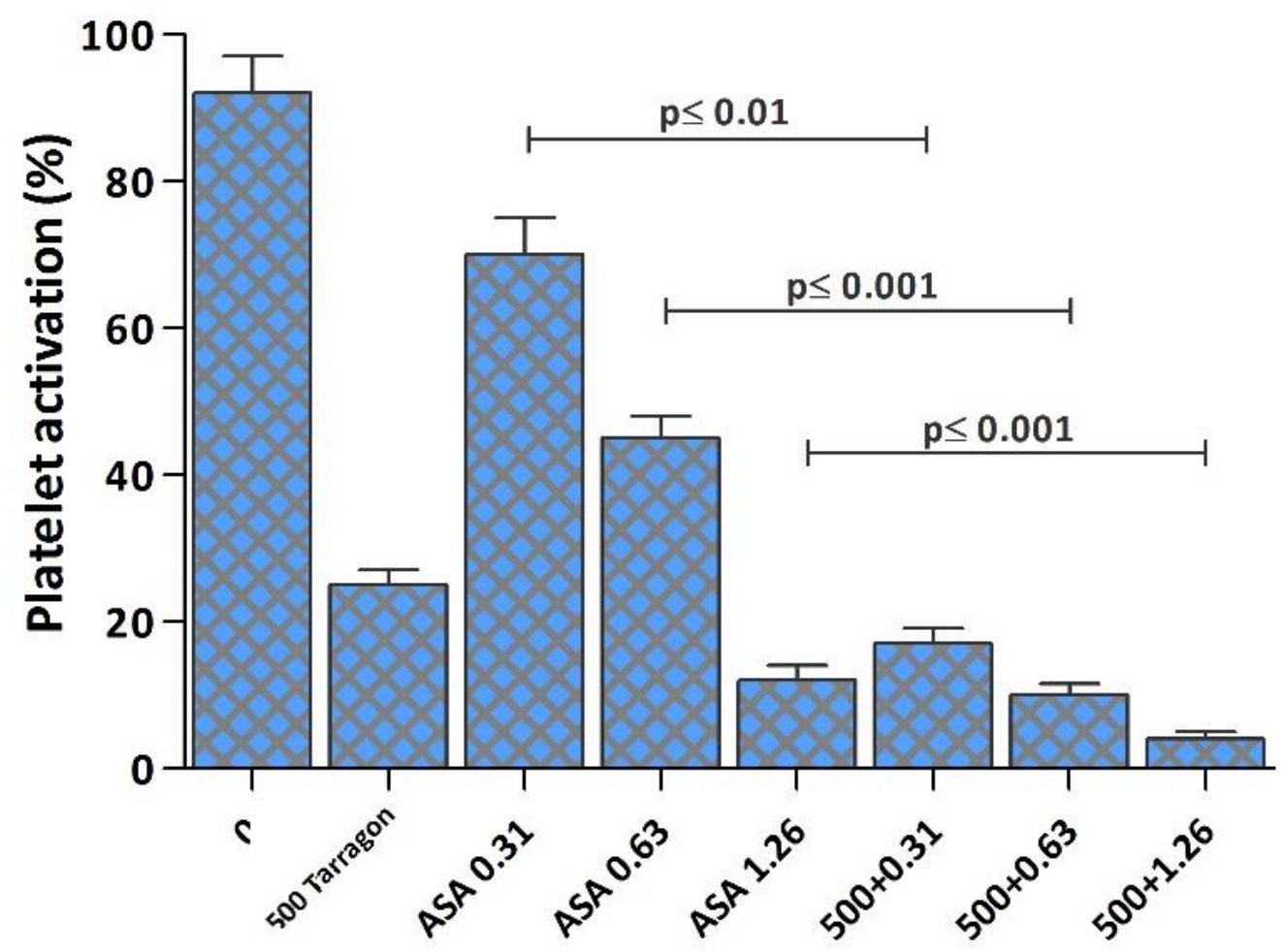

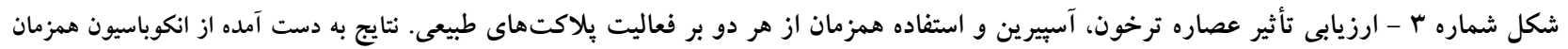

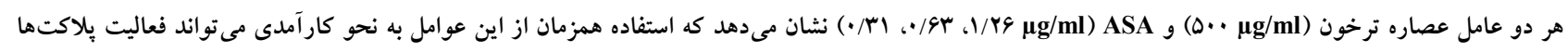

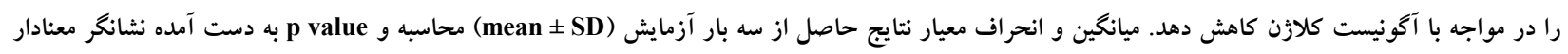
بودن نتايج از نظر آمارى در مقايسه با نمونه كتترل بود. 
تا ع ا و و 9 درصد شود كه اين نتيجه نشان مىدهد كه تركيب اين دو

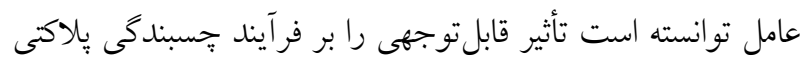

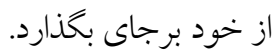

ارزيابى فعاليت رهاسازى (release) پِاكتى در انكوباسيون با عصاره ترخون، ASA و مواجه همزمان با هر دو ماده

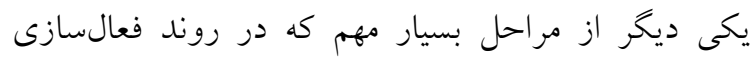

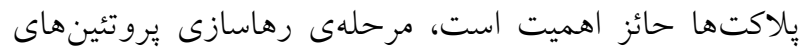

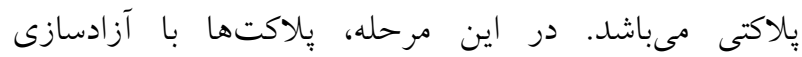

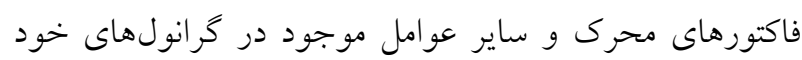

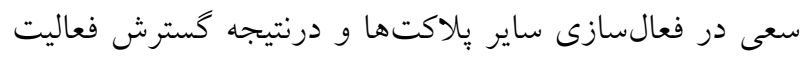

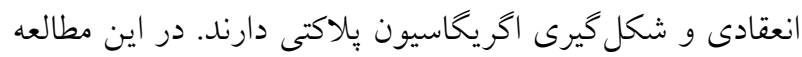

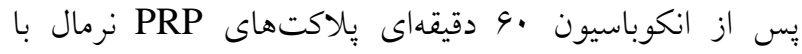

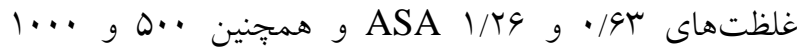

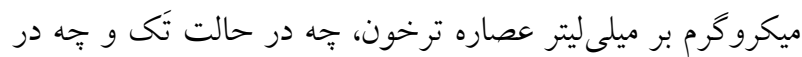

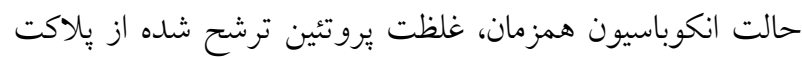

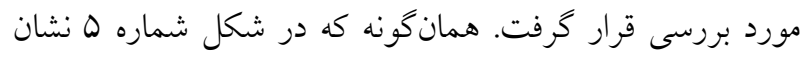

ارزيابى فعاليت جسبندگى هِاكتى در انكوباسيون با عصاره ترخون، ASA و مواجه همزمان با هر دو ماده

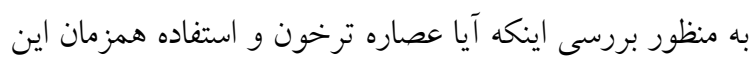

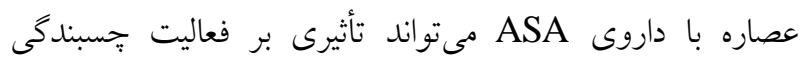

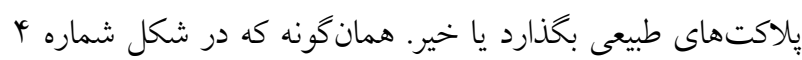

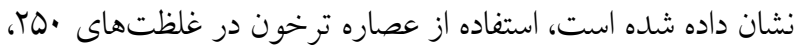

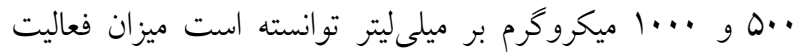

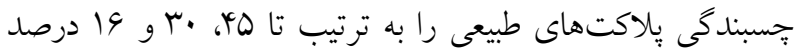

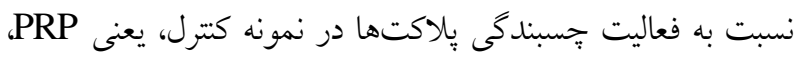

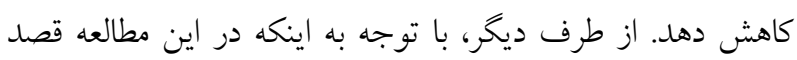

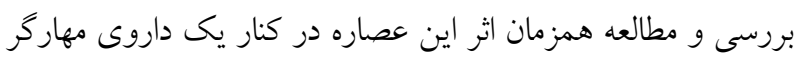

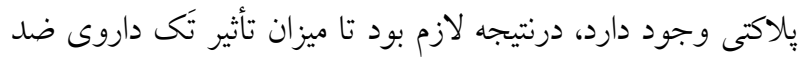
يلاكت ASA نيز مورد ارزيابى قرار كيرد. نتايج به دست امده نشان

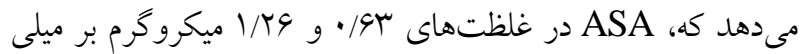

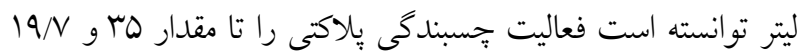

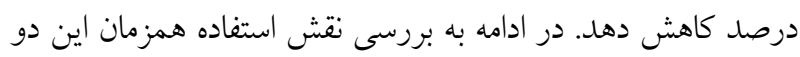

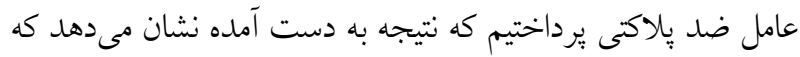

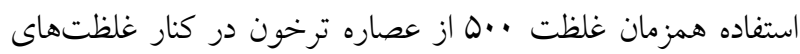
بو/ • و و 1/ از آسبيرين سبب كاهش قدرت جسبندكى يلاكتها

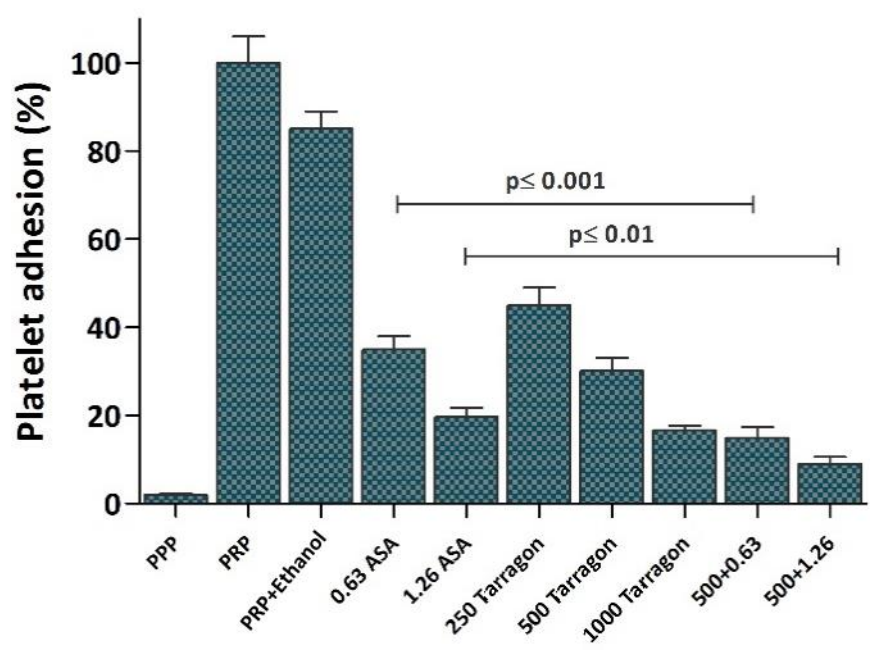

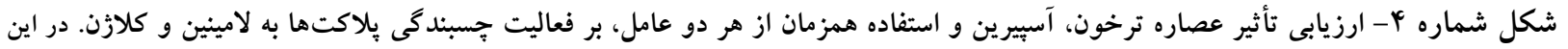

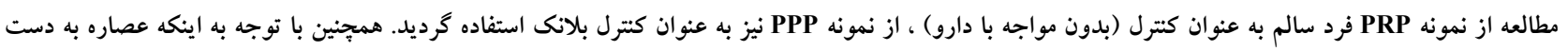

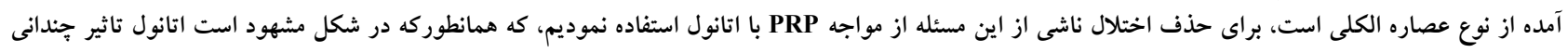

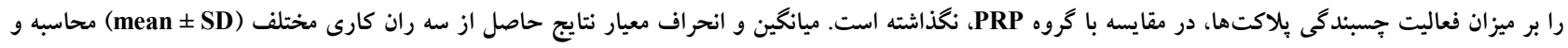

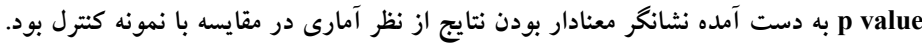




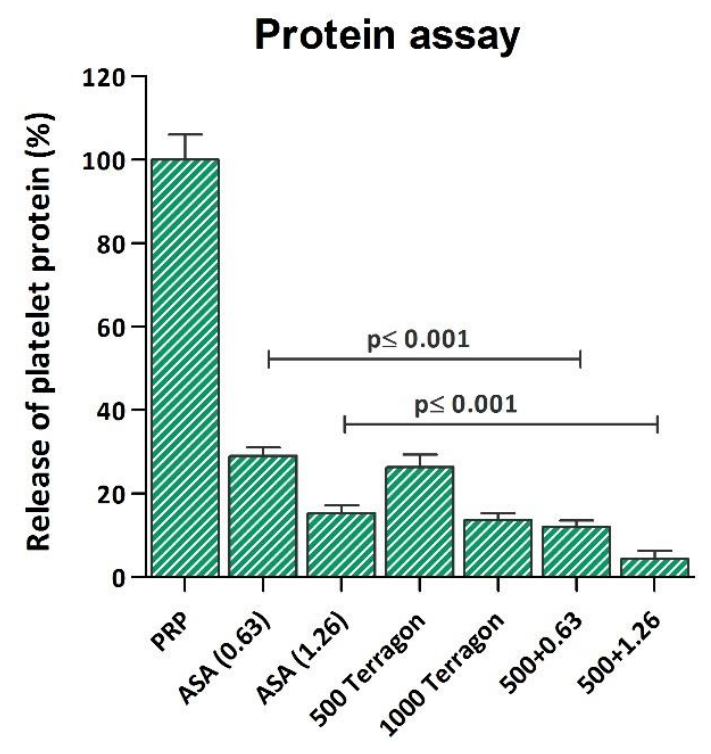

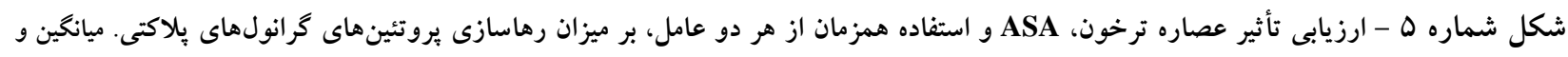

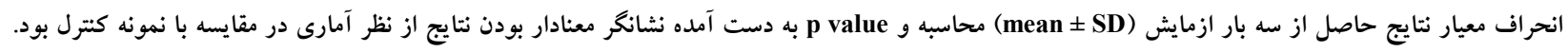

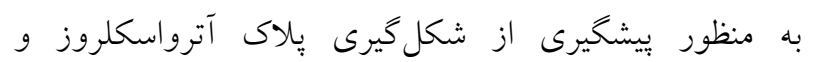

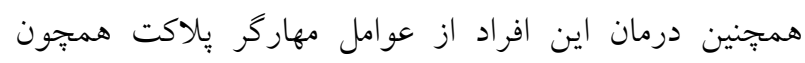

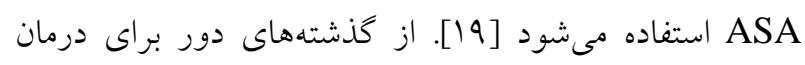

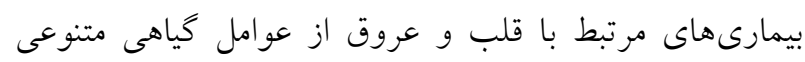

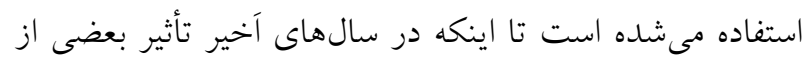

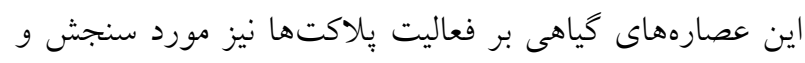

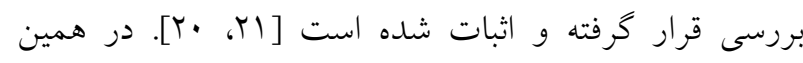
زمينه، ما مطالعهاى را طراحى كرديم تا تأثير عصاره تَرخون بر إنه

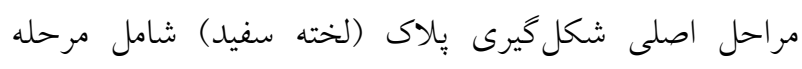

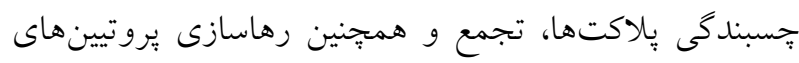
يلاكتى را مورد ارزيابى قرار دهيم.

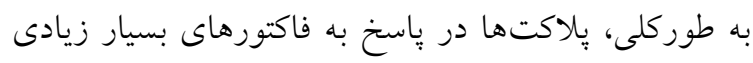

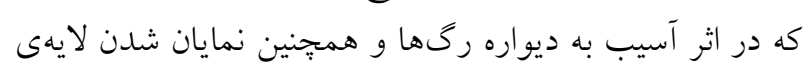

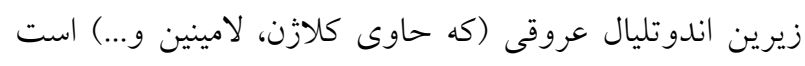

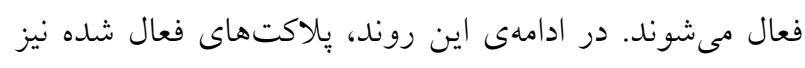

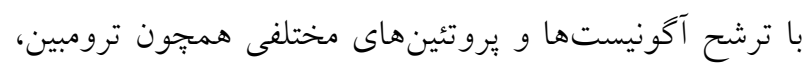

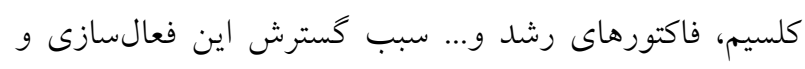

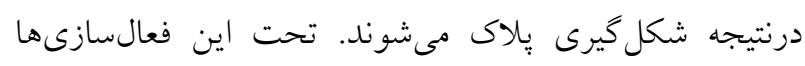

داده شده است، ميزان بروتئين ترشح شده از بِاكتهاى طبيعى (با

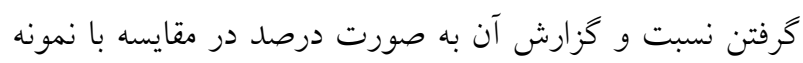

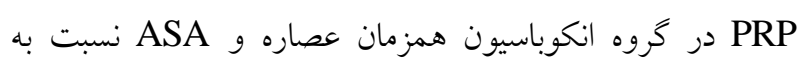

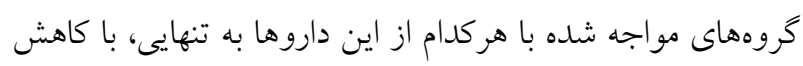

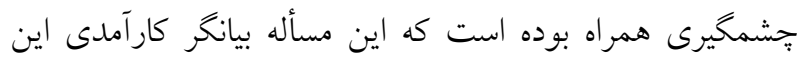

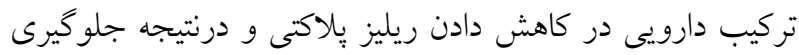
از گَترش اخريخاسيون بِاكتى مى باشد.

بهاكت هاى موجود در خون نقش بسيار مهمى را در فرآيند

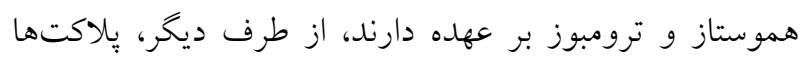

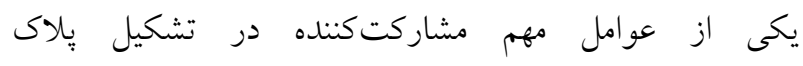

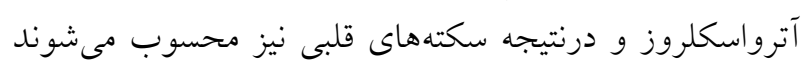

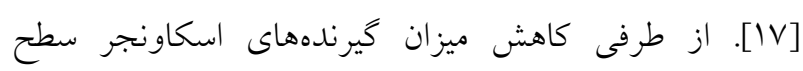

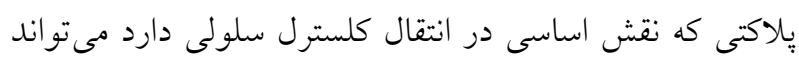

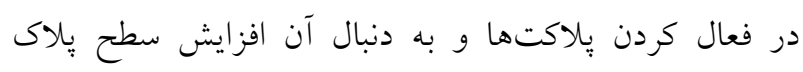

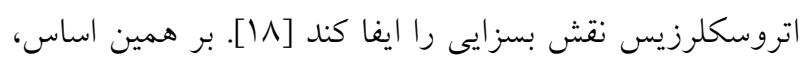


عصاره توانسته است در شرايط In vivo نيز فعاليت يلاكتى را

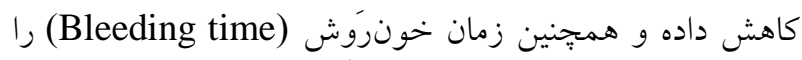

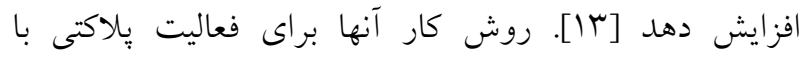

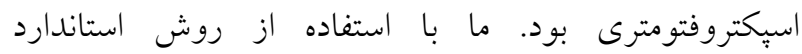

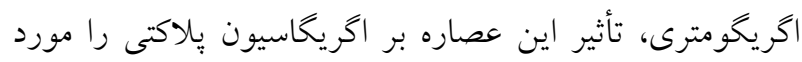

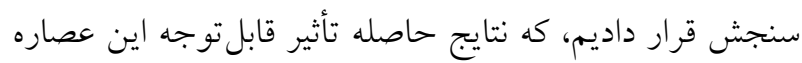

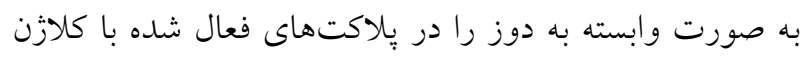

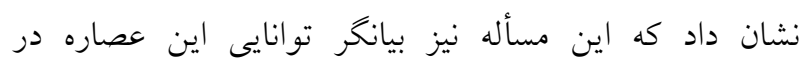

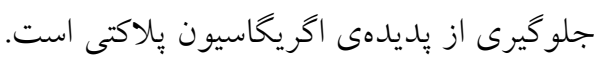

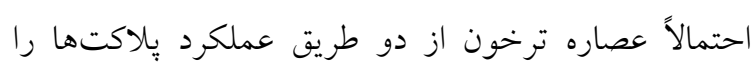

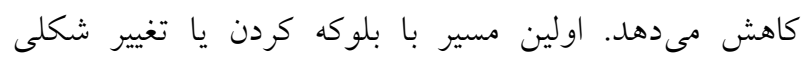

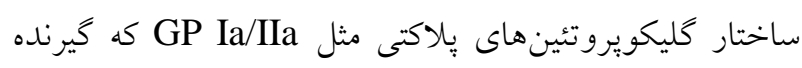

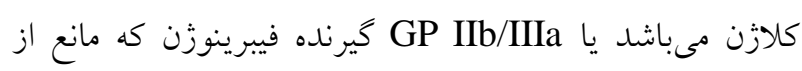

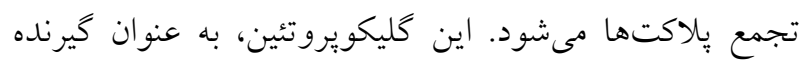

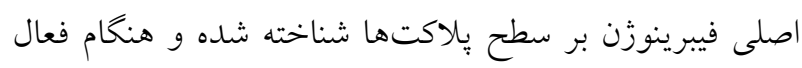

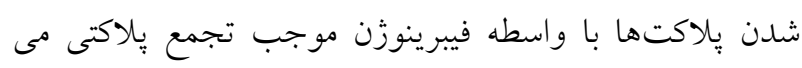

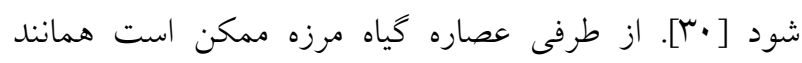

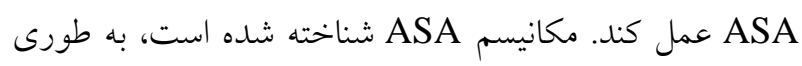

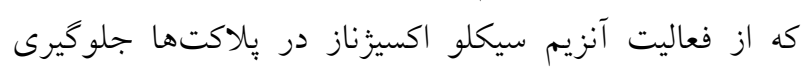

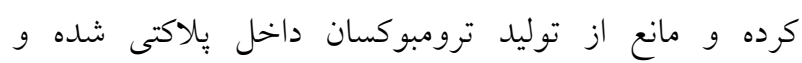

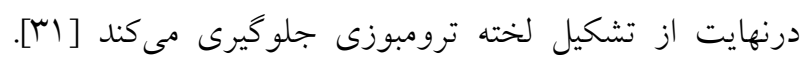

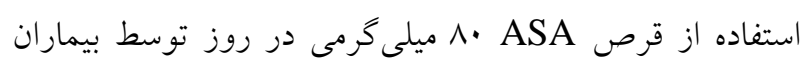

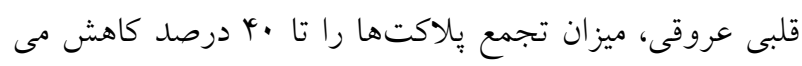

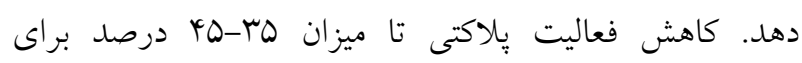

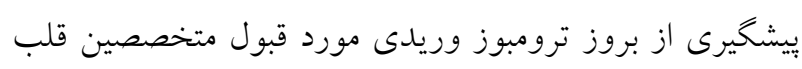

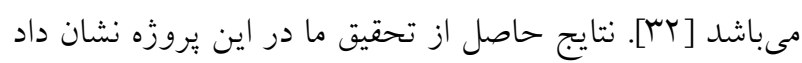

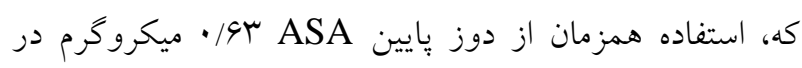

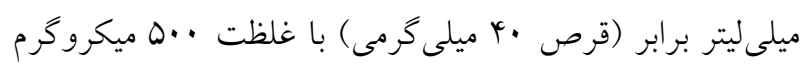

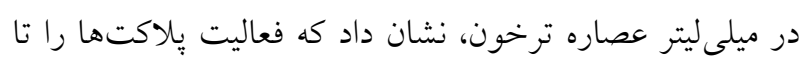
حدود ·r درصد كاهش داد.

\section{نتيجه گيرى}

در مجموع، يافتهاى به دست آمده بيانگر آن است كه اين

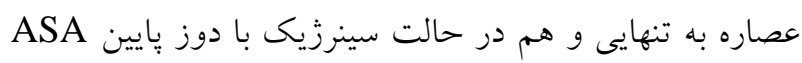

يلاكتها با تغيير شكل مورفولوزيك خود از فرم ديسكوئيدى

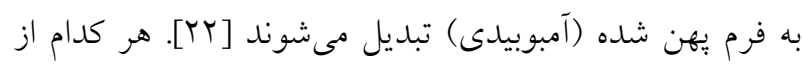

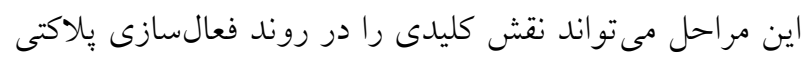

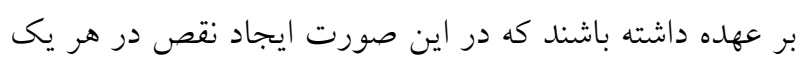

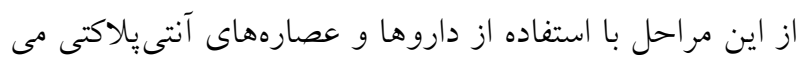

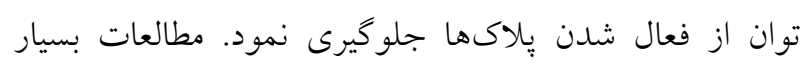

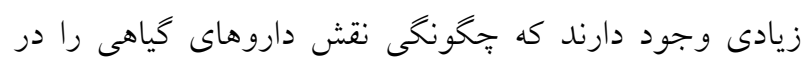

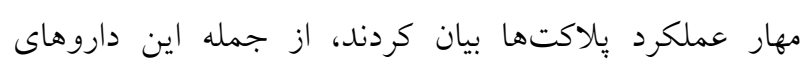

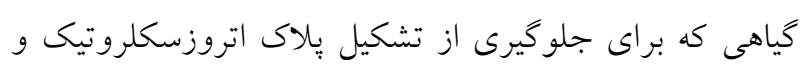

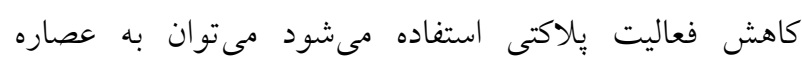

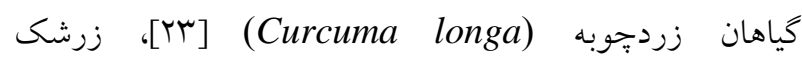

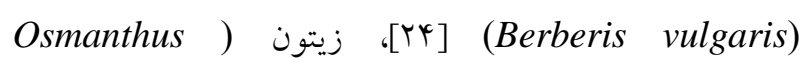
(fragrans

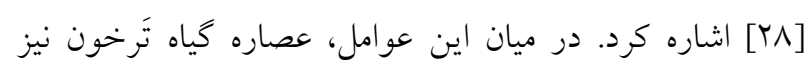

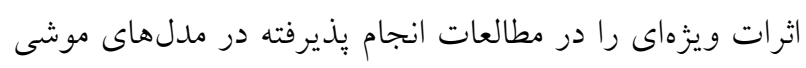

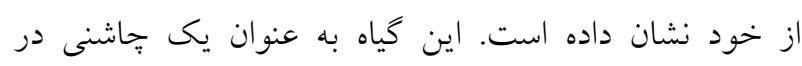

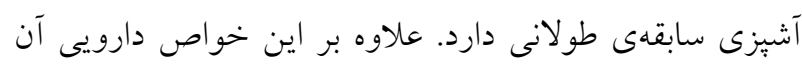

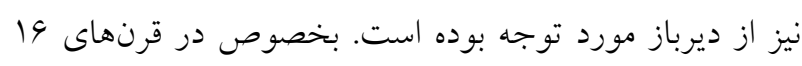

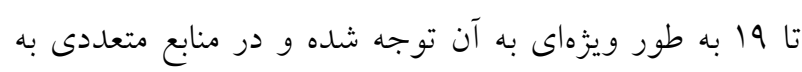

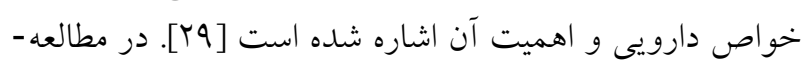

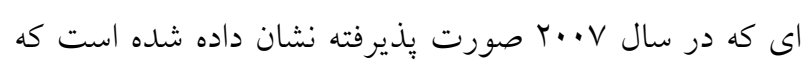

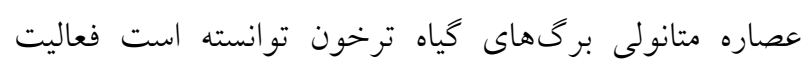

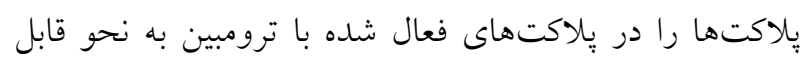

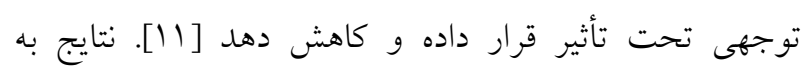

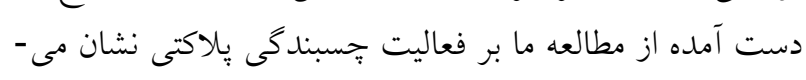

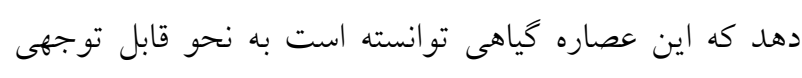

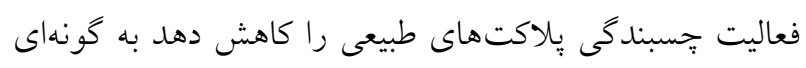

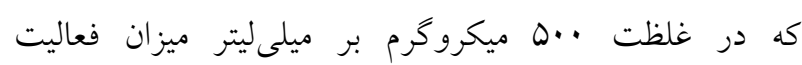

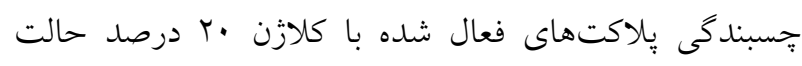
اوليه يعنى PRP كاهش يافته است، درنتيجه يافتهى ما نشان

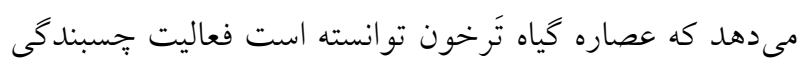

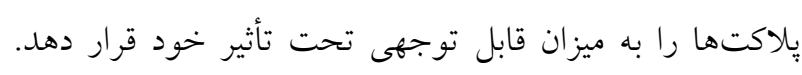

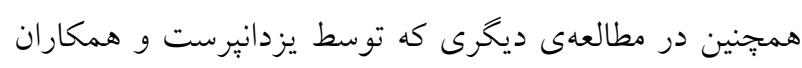

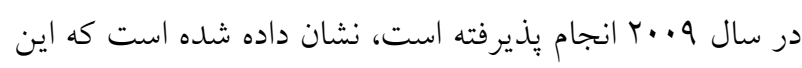




$$
\begin{aligned}
& \text { حيدريان و همكاران } \\
& \text { در درمان يِاك آترواسكلروز، بر عهلده دارند و همجنين استفاده } \\
& \text { از درمانهاى تركيبى نوينترى رادر اين افراد ايجاد نمايد. } \\
& \text { نتيجه به نظاند به نحو كارآمدى سبب مهار فعاليت پِاكتى شود و در كه اين عصاره بتواند رويكرد جديدى را }
\end{aligned}
$$

1. Sarrafzadegan N, Sadeghi M, Oveisgharan S and Iranipour R. Incidence of cardiovascular diseases in an Iranian population: the Isfahan Cohort Study. Archives of Iranian Medicine 2013; 16 (3): 138.

2. Shimokawa T, Smith W. Prostaglandin endoperoxide synthase .The aspirin acetylation region. J. Biological Chem. 1992; 267 (17): 12387-92.

3. Cooke GE, Liu-Stratton Y, Ferketich AK, Moeschberger ML, Frid DJ, Magorien RD and et al. Effect of platelet antigen polymorphism on platelet inhibition by aspirin, clopidogrel, or their combination. J. the American College of Cardiol. 2006; 47 (3): 541-6.

4. Folts JD, Crowell EB and Rowe GG. Platelet aggregation in partially obstructed vessels and its elimination with aspirin. Circulation 1976; 54 (3): 36570.

5. Massberg S, Brand K, Gruner S, Page S, Muller E, Muller I and et al. A critical role of platelet adhesion in the initiation of atherosclerotic lesion formation. The J. Experimental Medicine 2002; 196 (7): 887-96.

6. Murphy KJ, Chronopoulos AK, Singh I, Francis MA, Moriarty H, Pike MJ and et al. Dietary flavanols and procyanidin oligomers from cocoa (Theobroma cacao) inhibit platelet function. The American $J$. Clinical Nutrition 2003; 77 (6): 1466-73.

7. Hamidpour R, Hamidpour S, Hamidpour M and Shahlari M. Cinnamon from the selection of traditional applications to its novel effects on the inhibition of angiogenesis in cancer cells and prevention of Alzheimer's disease, and a series of functions such as antioxidant, Anti cholesterol, anti diabetes, antibacterial, antifungal, nematicidal, acaracidal, and repellent activities. J. Traditional and Complementary Medicine 2015; 5: 66-70.
8. Hamidpour R, Hamidpour S, Hamidpour M, Shahlari M, Sohraby M, Shahlari N and Hamidpour R. Russian olive (Elaeagnus angustifolia L.): From a variety of traditional medicinal applications to its novel roles as active antioxidant, anti-inflammatory, anti-mutagenic and analgesic agent. Journal of Traditional and Complementary Medicine 2017; 7: 24-29.

9. Khorasani MH. Makhzan al adviah. Safa Publication, Tehran. 1992, pp: 583-584.

10. Obolskiy D, Pischel I, Feistel B, Glotov N and Heinrich M. Artemisia dracunculus L. (tarragon): a critical review of its traditional use, chemical composition, pharmacology, and safety. $J$. Agricultural and Food Chem. 2011; 59 (21): 11367-84.

11. Shahriyary RY L. Antiplatelet and Antithrombotic Activities of Artemisia dracunculus L. Leaves Extract. Pharmacologyonline 2009; 1 (217): 2-8.

12. Rechinger K. H. and et al. Flora Iranica: Flora des iranischen Hochlandes und der umrahmenden Gebirge, Graz, Austria, 1971, 240-241.

13. Shahriyary L and Yazdanparast R. Inhibition of blood platelet adhesion, aggregation and secretion by Artemisia dracunculus leaves extracts. J. Ethnopharmacol. 2007; 114 (2): 194-8.

14. Lianne Kokoska, Dana El Masri, Helen Berlie and Candice Garwood. Aspirin prescribing patterns for primary prevention of cardiovascular disease in geriatric patients with diabetes: Survey of prescribers based on experience. Journal of Clinical Gerontology \& Geriatrics 2016; 7: 33-36.

15. Eriksson AC and Whiss PA. Measurement of adhesion of human platelets in plasma to protein surfaces in microplates. J. Pharmacological and Toxicological Methods 2005; 52 (3): 356-65.

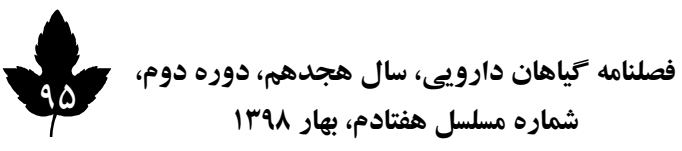


16. Lowry OH, Rosebrough NJ, Farr AL and Randall RJ. Protein measurement with the Folin phenol reagent. J. Biological Chem. 1951; 193 (1): 265-75.

17. Willoughby S, Holmes A and Loscalzo J. Platelets and cardiovascular disease. European journal of cardiovascular nursing: J. the Working Group on Cardiovascular Nursing of the European Society of Cardiol. 2002; 1 (4): 273-88.

18. Nehzati P, Hamidpour $M$, Bashash $D$, Nikoogoftar M, Hedari MR and Khadem Mabodi AA. The Detection of HDL receptor on platelet surface in patients with Coronary artery disease (CAD). J. Paramedical Sci. 2017; 8 (1): 33-38.

19. Schrader BJ and Berk SI. Antiplatelet agents in coronary artery disease. Clinical Pharmacy 1990; 9 (2): 118-24.

20. Mohd Nor NH, Othman F, Mohd Tohit ER and Md Noor S. Medicinal Herbals with Antiplatelet Properties Benefit in Coronary Atherothrombotic Diseases. Thrombosis 2016; 2016: 1-7.

21. Murphy KJ, Chronopoulos AK, Singh I, Francis MA, Moriarty $\mathrm{H}$, Pike MJ and et al. Dietary flavanols and procyanidin oligomers from cocoa (Theobroma cacao) inhibit platelet function. The American J. Clinical Nutrition 2003; 77 (6): 1466-73.

22. Ghezelbash B, Amini kafiabad S, Hojjati MT, Hamidpour M, Vaeli Sh, Tabtabae MR and Gharehbaghian A. In Vitro Assessment of Platelet Lesions during 5-day Storage in, Iraninan Blood Transfusion Organization (IBTO) centers. Archives of Iranian Medicine 2015; 18 (2): 114-116.

23. Prakash P, Misra A, Surin WR, Jain M, Bhatta RS, Pal R and et al. Anti-platelet effects of Curcuma oil in experimental models of myocardial ischemia-reperfusion and thrombosis. Thrombosis Res. 2011; (2) 127: 111-118.

24. Huang CG, Chu ZL, Wei SJ, Jiang H and Jiao BH. Effect of berberine on arachidonic acid metabolism in rabbit platelets and endothelial cells. Thrombosis Res. 2002; 106 (4-5): 223-7.
25. Tang $\mathrm{W}$, Cao J, Zhang $X$ and Zhao $Y$. Osmanthus fragrans seeds, a source of secoiridoid glucosides and its antioxidizing and novel plateletaggregation inhibiting function. Journal of Functional Foods 2015; 14: 337-44.

26. Teng CM, Chen CC, Ko FN, Lee LG, Huang TF, Chen YP and et al. Two antiplatelet agents from Magnolia officinalis. Thrombosis Res. 1988; 50 (6): 757-65.

27. Hamidpour R, Hamidpour S, Hamidpour M, Shahlari M and Sohraby M. Summer Savory: From the Selection of Traditional Applications to the Novel Effect in Relief, Prevention, and Treatment of a Number of Serious Illnesses such as Diabetes, Cardiovascular Disease, Alzheimer 's Disease, and Cancer. Journal of Traditional and Complementary Medicine 2014; 4: 140 - 144.

28. Banerjee SK and Maulik SK. Effect of garlic on cardiovascular disorders: a review. Nutrition J. 2002; 1: 4-10.

29. Obolskiy D, Pischel I, Feistel B, Glotov N and Heinrich M. Artemisia dracunculus L. (tarragon): a critical review of its traditional use, chemical composition, pharmacology, and safety. $J$. Agricultural and Food Chem. 2011; 59 (21): 11367-84.

30. Paolo Gresele, Jos'eA. L'opez, Clive P. Page, JosVermylen: Platelets in hematologic and cardivascular disorders. Cambride: Cambridge University Press, 2007, 26-27.

31. Dai $Y$ and Ge J. Clinical use of aspirin in treatment and prevention of cardiovascular disease. Thrombosis 2012; 2012: 1-7.

32. Lianne Kokoska, Dana El Masri, Helen Berlie and Candice Garwood. Aspirin prescribing patterns for primary prevention of cardiovascular disease in geriatric patients with diabetes: Survey of prescribers based on experience. J. Clinical Gerontology \& Geriatrics 2016; 7: 33-36. 


\title{
The Synergic Effect of Artemisia Dracunculus (Tarragon) Extract and Aspirin (ASA) on Platelet Function
}

\author{
Hedaryan AH (M.Sc.) ${ }^{1}$, Hamidpour M (Ph.D.) ${ }^{2 *}$, Ayatolahi AM (Ph.D.) ${ }^{3}$, Allah bakhshian \\ Farsiani M (Ph.D.) $)^{2}$
}

\begin{abstract}
1- Department of Hematology and Blood Banking, School of Allied Medicine Sciences, Shahid Beheshti University of Medical Sciences, Tehran, Iran

2- HSCT Research Center-Department of Hematology and Blood Banking, School of Allied Medicine Sciences, Shahid Beheshti University of Medical Sciences, Tehran, Iran

3- Phytochmistry Research Center, School of Pharmacy, Shahid Beheshti University of Medical Sciences, Tehran, Iran

*Corresponding author: Department of Hematology and Blood Banking, School of Allied Medicine Sciences, Shahid Beheshti University of Medical Sciences, HSCRC- Shahid Beheshti University of Medical Sciences, Tehran, Iran

Tel: +98-21-22717504, Fax: +98-21-22721150

E-mail: mohsenhp@sbmu.ac.ir
\end{abstract}

\begin{abstract}
Background: Coagulation activity of platelets plays an important role in thrombosis formation, Atherosclerotic plaque establishment and cardiovascular disorders. ASA are using as an anti platelet activity drug for patients with Coronary Artery Disease (CAD). Using of plant extraction as a complementary medicine for these patients (CAD) is mostly recommended by traditional medicine specialist.

Objective: In this study we investigated platelet activity after treatment with extract of Artemisia dracunculus (Tarragon) and it's synergic with ASA treatment.

Methods: After preparation of platelets from healthy volunteers, platelets confronted with desired concentrations $(125-1000 \mu \mathrm{g} / \mathrm{ml})$ of methanol extract of Artemisia dracunculus (tarragon) and $(0.31-1.26 \mu \mathrm{g} / \mathrm{ml})$ of (ASA) alone and in combination. The platelet function such as adhesion, aggregation and protein release were assayed on treated platelets and controls.

Results: Our results demonstrated that Tarragon extract significantly effective on adhesion, aggregation and protein release in comparison with healthy volunteers platelets $(P \leq 0.001)$. The Tarragon extract also raised the anti-platelet activity of ASA on these platelets.

Conclusion: Tarragon extract, either as single agent or combination with ASA, has been able to induce anti-platelet activity. Therefore, it would be suggested to use of the tarragon extract with or without common treatments, i.e. ASA, in treatments of cardiovascular disorders and patients with deep vein thrombosis.
\end{abstract}

Keywords: Artemisia dracunculus, Platelet activity, Platelet inhibitor, Terragon 